\title{
Principal sources of dietary fat in Australia: evidence from apparent consumption data and the national dietary survey of adults
}

\author{
BY KAREN M. CASHEL* \\ School of Biomedical Sciences, University of Canberra, P.O. Box 1, Belconnen, Australian Capital \\ Territory 2616, Australia \\ AND HEATHER GREENFIELD \\ Department of Food Science and Technology, University of New South Wales, P.O. Box 1, \\ Kensington, New South Wales 2033, Australia
}

(Received 26 April 1993-Revised 26 July 1993-Accepted 28 July 1993)

\begin{abstract}
The present study evaluates the evidence about the principal sources of fat in the Australian diet from the national per capita food supply data (apparent consumption; AC) and the national dietary survey of 6255 adults aged 25 to 64 years (NDSA). The AC and the NDSA data were converted to, and expressed on, an equivalent food basis to allow appropriate comparisons of foods consumed, and food sources of dietary fat. The AC figures showed that the principal sources of fat nationally were meat, edible fats, fat spreads and oils, and milk and milk products. As an estimate of adult food consumption the AC underestimated beef and veal, lamb, total meat, and poultry consumption by $41,10,29$ and $13 \%$ respectively, and overestimated offal, milk and milk products, and fats and oils by 15, 61, 20, and $29 \%$ respectively. The $\mathrm{AC}$ data rated fat spreads and cooking fats as providing more of the fat in the adult diet than did the NDSA, both in terms of total fat and fat as a percentage of energy. Conversely, on this same basis, the AC underrated meats as sources of fat in the adult diet. Other foods were of similar importance as sources of dietary fat in both sets of data. The $\mathrm{AC}$ markedly underestimated adult fat intake at $32 \%$ of energy compared with the NDSA result of $37 \%$. These results have implications for epidemiological research and for the development of food and nutrition policy and programmes in Australia and similar countries.
\end{abstract}

Fat intake: Food supply data: Adult food consumption: Animal foods

In Australia, as in many countries, the annual statistical data on the national food supplies available per capita have been used as the basis for determining trends in foods and nutrients consumed by the population. These apparent consumption (AC) data, based on food disappearance statistics, began with data for the 3 years ending 1938-39, the individual years 1944, 1945, 1946 and for 1946-47, and were first published in 1948 by the Commonwealth Bureau of Census and Statistics. In this inaugural issue, entitled Report on Food Production and the Consumption of Foodstuffs and Nutrients in Australia, the data on the foods available per capita total population were assessed against those from the 1944 national household dietary survey (National Health and Medical Research Council, 1945) to determine the reliability of the food disappearance statistics methods used as a measure of foods consumed, and were stated to be in good agreement. However, no data were provided in the report to support this assertion.

The current data, entitled Apparent Consumption of Foodstuffs and Nutrients, Australia,

* For reprints. 
are produced primarily as part of an agricultural statistics data series compiling production, export, import and manufacturing information on primary agricultural products. The AC data are per capita population averages and represent food availability at a particular point in the food distribution system. Efforts are made to provide data at a stage in the food chain closest to the consumer (e.g. cheese, canned fruit). The data have been used historically by agricultural economists and as the basis for the Australian component of the Food and Agriculture Organization's Food Balance Sheets (Food and Agriculture Organization, $1980 ; 1984)$. This agricultural orientation has ensured a minimum of assumptions and few changes in compiling the data together with a limit on interpretation of the data. As a result, for its 50 year history the series has maintained remarkable consistency in the completeness and compatibility of data collected.

From the start the AC data have been used to determine the nutrients potentially available from the food supply relative to the Australian recommended dietary intakes (RDI) appropriately weighted for the age and sex characteristics of the total population. Thus, the AC have been used to demonstrate trends in nutrients supplied per capita, as well as foods. They have also been accepted more recently as the basis for formulating national food and nutrition policy, in particular the development of the dietary goals for Australia (Langsford, 1979), the deliberations and recommendations of the Government's Better Health Commission (English, 1987) and the subsequent nutrition recommendations of many major Australian health bodies (e.g. Working Party on Food and Nutrition Policy, 1984; Health Targets and Implementation Committee, 1988; National Health and Medical Research Council, 1989).

The AC data have frequently been misused and misunderstood in Australia (e.g. Dwyer \& Hetzel, 1980; Newell \& Skurray, 1987a,b; Australian Meat and Livestock Corporation, 1988; Australian Nutrition Foundation 1989) particularly in misinterpreting the food items included and in implying that they are a measure of actual consumption or that these data can be directly interpreted as being pertinent to population subgroups, particularly adults. AC data have usually been rejected as valid estimates of population food consumption if dietary survey data, by any method and on any healthy population group, are available. It has been claimed that the AC grossly overestimates food intakes, particularly of meat (Fantini \& MacDonald, 1987; Australian Meat and Livestock Corporation, 1988; Baghurst et al. 1988).

Recently, national dietary surveys have been carried out in Australia, namely the 1983 survey of 6255 adults aged 25-64 years (National Dietary Survey of Adults (NDSA); Cashel et al. 1986) and a 1985 survey of 5244 schoolchildren aged 10-15 years (English et al. 1988). These were the first surveys to report the foods consumed by these population groups on an Australia-wide basis. The methods used were the $24 \mathrm{~h}$ recall (Cashel et al. 1986) and the $24 \mathrm{~h}$ diet record (English et al. 1988) respectively. The only previous national dietary surveys in Australia were the 1936-37 nutritional surveys of children in inland Australia (Advisory Council on Nutrition, 1937a,b), the 1938 survey based on 2565 1 month domestic records completed by households in five capital cities (Advisory Council on Nutrition, 1939) and the 1944 survey based on adjusted per capita weekly household food supply use (National Health and Medical Research Council, 1945).

New food composition data recently became available to enable refinement of the AC data, which will continue to be the major national dietary index of the Australian population. The present study was undertaken to estimate total fat intake and the principal contributors of dietary fat at population level in Australia, and to compare the AC data for 1983-84 (Australian Bureau of Statistics, 1985; 1990) with the NDSA 1983 (Cashel et al., 1986) in respect to fat. The present study had the following subsidiary objectives: evaluating the $\mathrm{AC}$ data as estimates of sources of fat in the adult diet on a 'food as 
consumed' rather than a raw foods basis; identifying areas in which more work is needed to improve the $\mathrm{AC}$ data, particularly ways to maximize their usefulness for national food policy and planning purposes; and identifying ways in which future national dietary surveys could be improved.

\section{METHODS}

\section{Apparent consumption data}

In common with most national food disappearance data, the per capita availability of foods for consumption data are derived annually. They are the sum of commercial production, estimated home production, imports and opening stocks, minus exports, wastage, usage for processed foods, non-food usage and closing stocks.

Production, usage, and stock data are obtained from annual agricultural and manufacturing censuses, from commodity board records and from wholesale records. For foods such as milk, cheese, butter and alcoholic beverages, however, the equation is not used; the usual alternative is wholesale distribution data.

The foods are grouped together on a primary produce basis with some groupings relating to major processed foods (Australian Bureau of Statistics, 1985). These groupings have been retained for the purpose of this comparison with NDSA data with respect to animal foods, and fats and oils. The AC data are usually expressed as the 'raw' food with, depending on the food, some adjustment for wastage in the food system, for home production and/or on-farm consumption of produce (e.g. poultry, fish, fruit, vegetables), and for the diversion of foods for non-food use. No allowance is made for home wastage or non-food use (e.g. feeding pets). The per capita data are derived by dividing the total weight available for each food by the estimated national population for the year of food data collection.

The data for nutrients available were formerly calculated using the Tables of Composition of Australian Foods (Thomas \& Corden, 1977). This national reference has recently been completely revised and now contains almost exclusively Australian data (Cashel et al. 1989; English et al. 1990; Lewis \& English, 1990) which have been used to calculate the fat and energy available from the cooked meats, milk and milk products, poultry, eggs, fish, cereals and most of the fruits and vegetables. Most of the margarine and cooking fats data are of Australian origin (Wills et al. 1982).

\section{Dietary survey data}

The NDSA obtained information from May to November 1983 on the foods eaten by a sample of 6255 adults aged 24-65 years resident in the six State capital cities (Sydney, Melbourne, Brisbane, Perth, Adelaide and Hobart) and selected systematically from the Commonwealth Electoral Roll. At the 1981 census (Table 1) the age breakdown of the Australian population was $(\%)$ : $0-9$ years, $16.1 ; 10-15$ years, $10.5 ; 16-24$ years, 15.7 ; 25-64 years, 48.0 and 65 +years, 9.7 (Australian Bureau of Statistics, 1987). The capital cities surveyed comprised $63.9 \%$ of the national population, with total urban dwellers comprising $85.7 \%$ of the national population. The NDSA did not sample from the $14 \%$ national rural dwellers, the $2.3 \%$ in the Territories (Northern and Australian Capital Territories) nor from the $22 \%$ non-capital city urban dwellers. The population of $25-64-$ year-olds in each State capital varied from $39.7 \%$ in Tasmania, the least urbanized State, to $78.8 \%$ in South Australia. The total State capital city 24-65-year-olds represented $61.6 \%$ of the $48 \%$ of the Australian population in this age group (Castles, 1986).

The dietary information was collected by trained interviewers using the $24 \mathrm{~h}$ recall method with extensive visual aids to assist with the assessment by participants of quantities of foods consumed. As the dietary survey was conducted in conjunction with the National 
Table 1. Population of Australia and its regions at 1981 census (\%)

\begin{tabular}{|c|c|c|c|c|c|c|c|c|}
\hline & $\begin{array}{l}\text { New } \\
\text { South } \\
\text { Wales }\end{array}$ & Victoria & Queensland & $\begin{array}{l}\text { South } \\
\text { Australia }\end{array}$ & $\begin{array}{c}\text { West } \\
\text { Australia }\end{array}$ & Tasmania & Territories* & Australia \\
\hline Total population & $35 \cdot 1$ & $26 \cdot 5$ & $15 \cdot 7$ & 8.8 & 8.9 & $2 \cdot 9$ & $2 \cdot 3$ & 100 \\
\hline $\begin{array}{l}\text { Population of } \\
\text { State capital }\end{array}$ & $62 \cdot 7$ & $71 \cdot 1$ & $46 \cdot 7$ & $72 \cdot 3$ & 70.9 & $40 \cdot 1$ & $77.9 \dagger$ & 63.9 \\
\hline $\begin{array}{l}\text { Age group 25-64 } \\
\text { in State capital }\end{array}$ & $62 \cdot 8$ & $70 \cdot 5$ & $41 \cdot 7$ & 78.8 & 71.6 & 39.7 & $49 \cdot 0$ & 61.7 \\
\hline Urban & $88 \cdot 2$ & 87.8 & $79 \cdot 1$ & $84 \cdot 9$ & $84 \cdot 6$ & $75 \cdot 1$ & $90 \cdot 3$ & $85 \cdot 7$ \\
\hline Rural & 11.8 & $12 \cdot 1$ & 20.8 & $15 \cdot 1$ & $15 \cdot 3$ & 24.6 & $9 \cdot 5$ & 14.2 \\
\hline
\end{tabular}

* Northern Territory and Australian Capital Territory.

$\dagger$ Average of Northern Territory (46.1) and Australian Capital Territory (99.5).

Heart Foundation's Risk Factor Prevalence Study (National Heart Foundation, 1984), the $24 \mathrm{~h}$ recall was selected as the best approach available to minimize respondent burden and information bias while optimizing response rates and, thus, the representative nature of the information obtained. While no specific validation component was attached to this study, this method is reported to be valid for providing information on mean dietary intakes by population groups (Block, 1982; Pao et al, 1989).

The data were adjusted to the age, sex and city of residence characteristics of the population as estimated from the 1981 National Census to obtain mean per capita intakes of foods. The days surveyed were ( $\%$ of total consumption days): Sunday, $17 \cdot 9$; Monday, 19.5; Tuesday, 20.0; Wednesday, 19.3; Thursday, 19.6; Friday, 3.6 and Saturday, 0.0. Details of the sample and the method of dietary intake measurement are given by Cashel et al. (1986).

The British food composition tables, McCance and Widdowson's The Composition of Foods (Paul \& Southgate, 1978) were selected before conducting the NDSA in 1983 to form the basis for the nutrient table to be used in determining the nutrients consumed. The British data were modified to include new Australian data for meat, poultry, take-away foods, some fruit, vegetables, and margarines and cooking fats, including commercial baking fats, to adjust for differences in nutrient fortification practices (e.g. in flours), and to allow for differences in cooking practices, and for some foods, e.g. fish, a selected set of data was used. The selection was based on incomplete Australian data then available that indicated significant differences in the nutrient content of equivalent foods. British data were used for milk products, with modifications to allow for known differences in the Australian food.

\section{Adjustments to data}

To compare the 1983-84 AC report with the 1983 NDSA (May to November) it was necessary to adjust the food data into equivalent or comparable forms. The AC data are for the foods available at a particular stage in the food distribution chain. The food quantity may or may not be in the form as eaten, and, as expressed in the annual bulletins, little or no allowance is made for such factors as inedible waste, cooking losses or weight change on cooking or processing. The NDSA data are for the foods in the form and quantity reported as consumed. The $\mathrm{AC}$ data were therefore converted to the edible weight equivalent of the food as consumed, including cooked or 'as prepared', where relevant. The reverse approach was considered, but rejected because it had a higher potential for error. 
Transforming foods from the 'as consumed' description to 'as available' in the food supply required more steps and assumptions to be made, particularly about foods such as meats.

The specific adjustments made to individual food groups were as shown below.

Meat and meat products. The AC boneless meat proportion of carcass meats shown in the Australian Bureau of Statistics (ABS) bulletin was calculated from recent information on the gross composition and weight changes on cooking of a wide range of Australian retail meat cuts (Greenfield, 1987). These data, together with data from the Meat and Allied Trades Federation (personal communication) on the proportion of retail cuts obtained from the different meat carcasses, were used to determine factors for the weighted edible portion of individual boneless meats and factors for the weighted average cooking loss from individual boneless meats. For cured pigmeat carcass the revised edible portion factor was used in conjunction with a factor for the weight change on curing used by the ABS (T. Bains, personal communication; Saxelby, 1987). The AC carcass weights of meats were then converted to an equivalent weight of cooked boneless meat (Table 2). Retail fat trimmings were excluded from consideration in determining meat available for consumption. These fats may be used in the production of frying fats, cooking margarines and shortenings and are included as such.

The NDSA consumption data were for the boneless, cooked edible weight of meat. A proportion of the meat consumed was reported to be trimmed of fat before consumption. These home fat trimmings are expected to be discarded. For the purpose of the survey, home fat trimming had been consistently treated as having $75 \%$ of separable fat removed. The reported and the untrimmed equivalent weights of meat were therefore determined. Using the recently published data on gross composition of purchased retail and then cooked meats (Greenfield, 1987), reported trimmed weights in the NDSA were converted to the untrimmed, cooked equivalent weight of meat. Where meat had been consumed as part of a mixed dish, the proportion by weight of the meat component was estimated from recipes (e.g. Paul \& Southgate, 1978) and from published gross and nutrient composition data for products (e.g. Greenfield et al. 1981; Wills et al. 1981). For pigmeats the bacon component of the NDSA was converted to a raw cured weight and added to the ham data to give a cured pigmeat intake comparable with the AC data.

Poultry. The AC cooked edible meat and skin weight equivalent of the dressed weight of bird was determined using factors from the Australian food composition tables (Cashel et al. 1989). The poultry consumption data from the NDSA were for the boneless cooked weight of meat and skin, or of meat only. The reported and the untrimmed (meat and skin) equivalent weights of meat were calculated. The NDSA poultry consumption reported as 'cooked meat portion only' was adjusted to the cooked meat and skin equivalent, using factors from the British food composition tables (Paul \& Southgate, 1978) as these were used at the time of the survey. The poultry component of mixed dishes was determined as described for meat products (e.g. Wills \& Greenfield, 1982b).

Fish and seafoods: The AC data for fish and seafoods are for the edible weight. These were adjusted to a cooked equivalent weight using factors derived from the revised Australian food composition tables (Lewis \& English, 1990). The fish and seafood components of mixed dishes consumed in the NDSA were determined as described for meat products and included in the total fish and seafood intake estimates.

Milk products. The AC data are given for the product weight (i.e. milk, cheese, cream, powdered and evaporated milks).

The NDSA respondents provided consumption information on specific milk products and also, in most cases, specified the milk component of all home-prepared foods containing milk. Some commercial foods such as quiche, cakes and biscuits could have contained milk or its products but the specific food descriptions were not sufficient to 
Table 2. Boneless raw and cooked edible-weight equivalents of representative beef, veal, lamb and pork carcasses (\% carcass)

\begin{tabular}{|c|c|c|c|c|}
\hline Retail cuts & $\begin{array}{c}\text { Whole } \\
\text { carcass* }\end{array}$ & $\begin{array}{c}\text { Boneless } \\
\text { raw edible } \\
\text { proportion }{ }^{\dagger}\end{array}$ & $\begin{array}{l}\text { Carcass } \\
\text { cooked } \\
\text { weight }\end{array}$ & $\begin{array}{c}\text { Boneless } \\
\text { cooked edible } \\
\text { proportion }\end{array}$ \\
\hline \multicolumn{5}{|l|}{ Beef } \\
\hline Fillet steak & 1.00 & 1.0 & 0.7 & 0.7 \\
\hline Rump steak & 4.00 & $4 \cdot 0$ & $2 \cdot 6$ & $2 \cdot 5$ \\
\hline Sirloin steak, bone in & 6.25 & $5 \cdot 0$ & $4 \cdot 4$ & $3 \cdot 3$ \\
\hline Round steak & 3.75 & $3 \cdot 8$ & $2 \cdot 6$ & 2.6 \\
\hline Topside steak & 5.50 & $5 \cdot 5$ & 3.9 & 3.9 \\
\hline Silverside & 5.75 & 5.6 & 3.7 & 3.7 \\
\hline Skirt steak & $1 \cdot 50$ & 1.5 & 0.9 & 0.8 \\
\hline Rolled rib-steak/eye & $7 \cdot 75$ & 6.7 & $5 \cdot 5$ & $4 \cdot 5$ \\
\hline Blade steak & 6.25 & $8 \cdot 4$ & 5.9 & 5.9 \\
\hline Chuck steak & 7.50 & $9 \cdot 8$ & 5.9 & $5 \cdot 5$ \\
\hline Rolled brisket & $5 \cdot 25$ & 5.0 & $3 \cdot 1$ & 2.9 \\
\hline Gravy beef & $6 \cdot 25$ & ND & ND & ND \\
\hline Minced steak & $4 \cdot 75$ & $\ddagger$ & $\ddagger$ & + \\
\hline Sausage trimmings & 600 & $6 \cdot 0$ & $\mathrm{ND}^{+}$ & ND \\
\hline Total carcass meat & $71 \cdot 50$ & $62 \cdot 1$ & $39 \cdot 0$ & $36 \cdot 3$ \\
\hline Kidney & 0.25 & (all other) & (all other) & (all other) \\
\hline Bones and wastage & $16 \cdot 50$ & $(37.9)$ & $(61 \cdot 0)$ & $(63.7)$ \\
\hline Fat wastage $\S$ & $11 \cdot 75$ & & & \\
\hline Total carcass & $100 \cdot 00$ & $100 \cdot 0$ & $100 \cdot 0$ & $100 \cdot 0$ \\
\hline $\begin{array}{l}\text { Final carcass preparation factors, } \\
\text { adjusted for missing data }\end{array}$ & & $66 \cdot 2$ & $44 \cdot 4$ & $41 \cdot 4$ \\
\hline Factor previously used & & $79 \cdot 0$ & & $(49 \cdot 2) \|$ \\
\hline \multicolumn{5}{|l|}{ Veal } \\
\hline Shoulder (bone-in) & $15 \cdot 75$ & $10 \cdot 6$ & 7.6 & 6.7 \\
\hline Neck chop & 5.00 & ND & ND & ND \\
\hline Veal chop & $14 \cdot 25$ & $9 \cdot 8$ & $10 \cdot 6$ & 6.8 \\
\hline Leg fillet (bone-in) & 33.75 & $24 \cdot 3$ & $16 \cdot 8$ & $15 \cdot 8$ \\
\hline Forequarter/diced veal & $9 \cdot 50$ & $9 \cdot 5$ & $5 \cdot 9$ & 4.9 \\
\hline Shank & $4 \cdot 50$ & $2 \cdot 1$ & 3.6 & $1 \cdot 4$ \\
\hline Total carcass meat & $82 \cdot 75$ & $56 \cdot 3$ & $44 \cdot 4$ & $35 \cdot 6$ \\
\hline Kidney & 0.75 & (all other) & (all other) & (all other) \\
\hline Bones and wastage & $10 \cdot 00$ & $(43.7)$ & $(55 \cdot 6)$ & $(64 \cdot 4)$ \\
\hline Fat wastage $\S$ & $1 \cdot 50$ & & & \\
\hline Knuckle & 5.00 & & & \\
\hline Total carcass & $100 \cdot 00$ & $100 \cdot 0$ & $100 \cdot 0$ & $100 \cdot 0$ \\
\hline $\begin{array}{l}\text { Final carcass preparation factors, } \\
\text { adjusted for missing data }\end{array}$ & & $59 \cdot 3$ & $46 \cdot 7$ & $37 \cdot 5$ \\
\hline Factor previously used & & $77 \cdot 0$ & & $(48 \cdot 7) \|$ \\
\hline \multicolumn{5}{|l|}{ Lamb } \\
\hline Leg & $23 \cdot 50$ & $18 \cdot 1$ & $18 \cdot 6$ & $13 \cdot 0$ \\
\hline Shoulder/forequarter & $16 \cdot 25$ & $11 \cdot 7$ & $11 \cdot 7$ & $8 \cdot 1$ \\
\hline Chump chops & $6 \cdot 25$ & $4 \cdot 8$ & $4 \cdot 2$ & $3 \cdot 2$ \\
\hline Short loin chop & $14 \cdot 00$ & $11 \cdot 3$ & 9.8 & $7 \cdot 3$ \\
\hline Cutlet & $5 \cdot 50$ & $4 \cdot 4$ & 3.9 & $3 \cdot 0$ \\
\hline Neck chops, scrag & 6.00 & $4 \cdot 0$ & $4 \cdot 2$ & $2 \cdot 7$ \\
\hline Sausage trimmings & $11 \cdot 00$ & 11.0 & ND & ND \\
\hline Total carcass meat & $82 \cdot 25$ & $65 \cdot 4$ & $52 \cdot 3$ & $37 \cdot 2$ \\
\hline
\end{tabular}


Table 2. (cont.)

\begin{tabular}{|c|c|c|c|c|}
\hline Retail cuts & $\begin{array}{l}\text { Whole } \\
\text { carcass* }\end{array}$ & $\begin{array}{c}\text { Boneless } \\
\text { raw edible } \\
\text { proportion } \dagger\end{array}$ & $\begin{array}{l}\text { Carcass } \\
\text { cooked } \\
\text { weight } \dagger\end{array}$ & $\begin{array}{c}\text { Boneless } \\
\text { cooked edible } \\
\text { proportion }\end{array}$ \\
\hline Scrag neck trim & 5.25 & (all other) & (all other) & (all other) \\
\hline Kidney & 0.50 & $(34 \cdot 6)$ & $(47 \cdot 7)$ & $(62.8)$ \\
\hline Bones and wastage & $6 \cdot 25$ & & & \\
\hline Fat wastage§ & 5.75 & & & \\
\hline Total carcass & $100 \cdot 00$ & $100 \cdot 0$ & $100 \cdot 0$ & $100 \cdot 0$ \\
\hline $\begin{array}{l}\text { Final carcass preparation factors, } \\
\text { adjusted for missing data }\end{array}$ & & $65 \cdot 4$ & $58 \cdot 8$ & 41.8 \\
\hline Factor previously used & & 78.0 & & $(51 \cdot 4) \|$ \\
\hline \multicolumn{5}{|l|}{ Pork } \\
\hline Leg & $25 \cdot 25$ & $22 \cdot 0$ & 16.9 & $13 \cdot 8$ \\
\hline Chop & $19 \cdot 50$ & $16 \cdot 8$ & 13.7 & $10 \cdot 2$ \\
\hline Foreloin/forequarter & 17.00 & 13.6 & 11.4 & 8.7 \\
\hline Hands & 11.75 & ND & ND & ND \\
\hline Springs & 8.00 & ND & ND & ND \\
\hline Total carcass meat & $81 \cdot 50$ & $52 \cdot 3$ & $42 \cdot 0$ & $32 \cdot 7$ \\
\hline Kidney & 0.50 & (all other) & (all other) & (all other) \\
\hline Bones and wastage & 3.75 & $(47 \cdot 7)$ & $(58 \cdot 0)$ & $(67 \cdot 3)$ \\
\hline Fat wastage $\S$ & $4 \cdot 25$ & & & \\
\hline Head & $10 \cdot 00$ & & & \\
\hline Total carcass & $100 \cdot 00$ & $100 \cdot 0$ & $100 \cdot 0$ & $100 \cdot 0$ \\
\hline $\begin{array}{l}\text { Final carcass preparation factors, } \\
\text { adjusted for missing data }\end{array}$ & & $65 \cdot 2$ & $52 \cdot 3$ & $40 \cdot 7$ \\
\hline Factors previously used & & $86 \cdot 0$ & & $(53 \cdot 7) \|$ \\
\hline
\end{tabular}

ND, no data.

* Personal communication, Meat and Allied Trades Federation.

+ Factors from Greenfield (1987).

\$ Included with blade and chuck steak in equal proportions. Rounded at completion of computations.

$\S$ May be used in edible fats and spreads; included with these.

|| Equivalent factor based on current basis for estimating boneless edible weight.

identify specifically and quantify the milk component. The total mean consumption of these foods was low (about $30 \mathrm{~g}$ maximum) and the milk proportion, if present, would have been small, of the order of $4 \mathrm{ml}$, with no significant effect on the results obtained. No estimate of the milk component for these foods was therefore attempted. A liquid wholemilk equivalent of milk products was calculated for the NDSA data on a protein-equivalent basis.

Eggs and egg products. In the AC the edible portion of the available egg supply was determined by deducting the weight of shell. In 1986-87 the ABS revised all egg data from 1981-82 onwards using State Egg Board data on commercial sales as the sole basis for reporting per capita available egg (Australian Bureau of Statistics, 1988). Previously an estimate of home production had been included.

From the NDSA, only the consumption of eggs as egg itself could be considered. Estimates of the egg component of mixed foods were only possible when specified within a recipe.

Oils and fats. The AC records fats as spreads (butter, table margarine and 'other' margarine) and a total for unspecified fats (e.g. dripping) and oils.

The NDSA recorded spreads and home-cooking use of fats and oils. For mixed foods 
where the participants could not specify the type and quantity of added fat used (e.g. in commercial bakery products) an estimate was made of the minimum quantity of added fat using manufacturers' information, analytical data (e.g. Wills \& Greenfield, $1982 a$; Greenfield et al. 1983) and recipe proportions (e.g. Paul \& Southgate, 1978). The most likely type of cooking fat (i.e. spread type, commercial shortening or cooking (frying) fat or oil) was also imputed from these sources of information, and categorized as either 'unspecified spread' or as (unspecified) 'cooking (frying) fat or oil'.

Food table. No adjustments were necessary as the food tables used in the study were comparable in terms of the fat content of foods, both being based mainly on Australian data. The NDSA applied the nutrient composition of individual meat cuts from the Australian food analytical programme (Cashel et al. 1989) to calculate fat and energy intakes, while the AC calculations used the same data, weighted across the carcass as outlined in Table 2, to determine the nutrients in cooked, boneless carcass meat.

\section{RESULTS}

The results for each product group were calculated as percentage deviation of the NDSA from the AC. Agreement was defined according to the following ratings: good agreement, up to $10 \%$ deviation from the $\mathrm{AC}$; fair, 11 to $20 \%$ deviation from the $\mathrm{AC}$; poor, 21 to $40 \%$ deviation from the AC; very poor, $41 \%$ or greater deviation from the AC.

\section{Consumption of foods by food group}

The terms 'consumed' and 'consumption' in this context apply to foods available for consumption (AC) and foods reported consumed by adults (NDSA).

Meat and meat products. The derivation of the factors for determining the boneless raw and cooked weight equivalent from the AC meat carcass weights is shown in Table 2. For beef, lamb and veal the data available are a reasonable representation of cuts across the carcass. The pork data are more limited and the resultant factors are not such a good representation for the carcass.

For cooked edible weight equivalent of meat from the carcass weight (Table 2) the data overall indicate that, on average, $1 \mathrm{~kg}$ carcass weight meat provides $635 \mathrm{~g}$ raw edible weight of meat or $400 \mathrm{~g}$ of cooked edible weight of meat. This varies from $595 \mathrm{~g}$ raw edible weight of meat $/ \mathrm{kg}$ from a veal carcass to $660 \mathrm{~g} / \mathrm{kg}$ from a beef carcass, and from $375 \mathrm{~g}$ cooked edible weight of meat $/ \mathrm{kg}$ from a veal carcass to $418 \mathrm{~g} / \mathrm{kg}$ from a lamb carcass.

The per capita cooked edible weights of meat from the AC and NDSA data are compared in Table 3. For the NDSA data the meat component of mixed foods is included. These inclusions account for $9.9 \mathrm{~g}$ of total beef, $0.6 \mathrm{~g}$ of lamb and/or mutton and $1.1 \mathrm{~g}$ of 'fresh' pigmeat. The NDSA data for veal were adjusted down by $0.3 \mathrm{~g}$ due to the deduction of the weight of coatings for some veal dishes. The NDSA data are also shown for the total untrimmed equivalent weight of meats reported consumed. The AC data are given using both the currently used and recalculated factors for determining the edible weight of meat on a carcass, with further adjustments to both to allow for cooking losses.

Smallgoods (e.g. delicatessen meats) reported consumed in the NDSA are given separately from other meats. These foods may, under food law, contain a small cereal component (e.g. up to $6 \mathrm{~g}$ starch/100 $\mathrm{g}$ for raw sausages) and recent studies have shown that some may contain mixed meat components (Greenfield \& Kosulwat, 1991). The meat component of these foods could be expected to comprise some $90 \%$ of the edible weight for most items.

These results show that $\mathrm{AC}$ data, when allowing for reported trimming, underestimate adult beef consumption (excluding small goods) by about $39 \%$, and about $47 \%$ on the 
Table 3. Per capita consumption of meats, poultry, fish, seafood and products: apparent consumption data (AC) 1983-84 and National Dietary Survey of Adults (NDSA) 1983 (boneless, cooked edible weight equivalent $\mathrm{g} / \mathrm{d}$ )

\begin{tabular}{|c|c|c|c|c|c|c|}
\hline \multirow[b]{3}{*}{ Food } & \multicolumn{2}{|c|}{ Apparent consumption } & \multicolumn{2}{|c|}{ Dietary survey } & & \\
\hline & \multirow{2}{*}{$\begin{array}{l}\text { Using } \\
\text { revised } \\
\text { factors (1) }\end{array}$} & \multirow{2}{*}{$\begin{array}{l}\text { Using } \\
\text { previous } \\
\text { factors (2) }\end{array}$} & \multirow{2}{*}{$\begin{array}{l}\text { As } \\
\text { reported } \\
\text { (3) }\end{array}$} & \multirow{2}{*}{$\begin{array}{l}\text { As purchased } \\
\text { equivalent* } \\
\text { (4) }\end{array}$} & \multicolumn{2}{|c|}{ NDSA/AC (\%) } \\
\hline & & & & & $(3 / 1)$ & $(4 / 1)$ \\
\hline Beef & 44.9 & $55 \cdot 4$ & $62 \cdot 5$ & 65.8 & +39 & +47 \\
\hline Veal & 2.5 & $3 \cdot 2$ & 4.5 & 4.5 & +80 & +80 \\
\hline Lamb and mutton & $25 \cdot 1$ & $31 \cdot 1$ & 27.6 & $30 \cdot 0$ & +10 & +20 \\
\hline Pigmeat, total & $20 \cdot 2$ & $26 \cdot 6$ & $20 \cdot 5$ & 21.9 & +1 & +8 \\
\hline Pigmeat, 'fresh' & $8 \cdot 6$ & $11 \cdot 3$ & 8.5 & $9 \cdot 6$ & -1 & +11 \\
\hline $\begin{array}{l}\text { Pigmeat, cured, raw } \\
\text { weight equivalent }{ }^{\dagger}\end{array}$ & $11 \cdot 6$ & $15 \cdot 3$ & $12 \cdot 0$ & $12 \cdot 3$ & +3 & +6 \\
\hline $\begin{array}{l}\text { Offal } \\
\text { Other smallgoods } \\
\text { sausages, beef } \\
\text { sausages, pork } \\
\text { frankfurters } \\
\text { delicatessen meats }\end{array}$ & $\begin{array}{l}9 \cdot 0 \\
\text { NA } \\
\text { NA } \\
\text { NA } \\
\text { NA } \\
\text { NA }\end{array}$ & $\begin{array}{l}9 \cdot 0 \\
\text { NA } \\
\text { NA } \\
\text { NA } \\
\text { NA } \\
\text { NA }\end{array}$ & $\begin{array}{r}3.5 \\
17.1 \\
7.2 \\
1.6 \\
1.8 \\
6.5\end{array}$ & $\begin{array}{r}3 \cdot 5 \\
17 \cdot 1 \\
7 \cdot 2 \\
1 \cdot 6 \\
1 \cdot 8 \\
6 \cdot 5\end{array}$ & $\begin{array}{l}-61 \\
\text { NA } \\
\text { NA } \\
\text { NA } \\
\text { NA } \\
\text { NA }\end{array}$ & $\begin{array}{l}-61 \\
\text { NA } \\
\text { NA } \\
\text { NA } \\
\text { NA } \\
\text { NA }\end{array}$ \\
\hline Total meat & $101 \cdot 7$ & $125 \cdot 3$ & $135 \cdot 7$ & $142 \cdot 8$ & +33 & +40 \\
\hline $\begin{array}{l}\text { Chicken } \ddagger \\
\text { Duck, turkey }\end{array}$ & $\begin{array}{r}20 \cdot 3 \\
2 \cdot 7\end{array}$ & $\begin{array}{l}\text { NR } \\
\text { NR }\end{array}$ & $\begin{array}{r}25 \cdot 0 \\
1.0\end{array}$ & $\begin{array}{r}27 \cdot 6 \\
1 \cdot 2\end{array}$ & $\begin{array}{l}+23 \\
-63\end{array}$ & $\begin{array}{l}+36 \\
-56\end{array}$ \\
\hline Total poultry & $23 \cdot 0$ & NR & $26 \cdot 0$ & $28 \cdot 8$ & +13 & +25 \\
\hline $\begin{array}{l}\text { Fish, non-processed } \\
\text { Crustacea, molluscs } \\
\text { Other processed fish }\end{array}$ & $\begin{array}{l}8 \cdot 3 \\
3 \cdot 3 \\
7 \cdot 1\end{array}$ & $\begin{array}{l}\text { NR } \\
\text { NR } \\
\text { NR }\end{array}$ & $\begin{array}{l}8 \cdot 7 \\
4 \cdot 3 \\
5 \cdot 4\end{array}$ & $\begin{array}{l}\text { NR } \\
\text { NR } \\
\text { NR }\end{array}$ & $\begin{array}{r}+5 \\
+30 \\
-24\end{array}$ & $\begin{array}{l}\text { NR } \\
\text { NR } \\
\text { NR }\end{array}$ \\
\hline Total fish and seafood & $18 \cdot 7$ & NR & $18 \cdot 4$ & NR & -2 & NR \\
\hline $\begin{array}{l}\text { Milk, liquid }(\mathrm{ml}) \| \\
\text { Evaporated/condensed milk }\end{array}$ & 277.6 & NR & $241 \cdot 4$ & NR & -13 & NR \\
\hline $\begin{array}{l}\text { sweetened, whole } \\
\text { sweetened, skimmed } \\
\text { unsweetened }\end{array}$ & $\begin{array}{l}1.9 \\
5 \cdot 5 \\
3 \cdot 3\end{array}$ & $\begin{array}{l}\text { NR } \\
\text { NR } \\
\text { NR }\end{array}$ & $\begin{aligned} & 0.7 \\
&< 0.05 \\
& 1.2\end{aligned}$ & $\begin{array}{l}\text { NR } \\
\text { NR } \\
\text { NR }\end{array}$ & $\begin{array}{l}-63 \\
\text { NA } \\
-64\end{array}$ & $\begin{array}{l}\text { NR } \\
\text { NA } \\
\text { NR }\end{array}$ \\
\hline $\begin{array}{l}\text { Powdered milk } \\
\text { whole } \\
\text { skimmed } \\
\text { Cheese } \\
\text { Cream } \\
\text { Yoghurt } \\
\text { Ice-cream } \\
\text { Other milk products }\end{array}$ & $\begin{array}{l}1 \cdot 9 \\
6.2 \\
22 \cdot 1 \\
2 \cdot 5 \\
\text { NA } \\
\text { NA } \\
18 \cdot 8\end{array}$ & $\begin{array}{l}\text { NR } \\
\text { NR } \\
\text { NR } \\
\text { NR } \\
\text { NR } \\
\text { NR } \\
\text { NR }\end{array}$ & $\begin{array}{r}0 \cdot 1 \\
0 \cdot 8 \\
18 \cdot 5 \\
5 \cdot 2 \\
6 \cdot 7 \\
12 \cdot 7 \\
22 \cdot 2\end{array}$ & $\begin{array}{l}\text { NR } \\
\text { NR } \\
\text { NR } \\
\text { NR } \\
\text { NR } \\
\text { NR } \\
\text { NR }\end{array}$ & $\begin{array}{r}-95 \\
-87 \\
-16 \\
+108 \\
\text { NA } \\
\text { NA } \\
+18\end{array}$ & $\begin{array}{l}\text { NR } \\
\text { NR } \\
\text { NR } \\
\text { NR } \\
\text { NA } \\
\text { NA } \\
\text { NR }\end{array}$ \\
\hline Total milk & $578 \cdot 0$ & NR & $427 \cdot 0$ & $427 \cdot 0$ & -26 & -26 \\
\hline Egg & $19 \cdot 6$ & NR & $19 \cdot 6$ & $19 \cdot 6$ & 0 & 0 \\
\hline $\begin{array}{l}\text { Butter } \\
\text { Margarine, table } \\
\text { Margarine, other } \\
\text { Spreads, not specified** } \\
\text { All table spreads } \\
\text { Cooking fats, oils }\end{array}$ & $\begin{array}{c}10 \cdot 5 \\
18 \cdot 9 \\
5 \cdot 7 \\
\mathrm{NA} \\
35 \cdot 1 \\
27 \cdot 3\end{array}$ & $\begin{array}{l}\text { NR } \\
\text { NR } \\
\text { NR } \\
\text { NR } \\
\text { NR } \\
\text { NR }\end{array}$ & $\begin{array}{r}7 \cdot 8 \\
9 \cdot 6 \\
2 \cdot 3 \\
9 \cdot 8 \\
29 \cdot 5 \\
14 \cdot 6\end{array}$ & $\begin{array}{l}\text { NR } \\
\text { NR } \\
\text { NR } \\
\text { NR } \\
\text { NR } \\
\text { NR }\end{array}$ & $\begin{array}{l}-26 \\
-49 \\
-60 \\
\text { NA } \\
-16 \\
-47\end{array}$ & $\begin{array}{l}\text { NR } \\
\text { NR } \\
\text { NR } \\
\text { NA } \\
\text { NR } \\
\text { NR }\end{array}$ \\
\hline Total fats and oils & $62 \cdot 4$ & NR & $44 \cdot 1$ & $44 \cdot 1$ & -29 & -29 \\
\hline
\end{tabular}

NA, not available; NR, not relevant.

* Trimmed meats and poultry adjusted to 'as purchased' cooked weights; for mixed foods, meat, poultry, fish, components included as such.

t Cooked bacon adjusted to cured weight, ham treated as cured product weight; no allowance for any nonmeat component.

+ Proportion of chicken to other poultry from Australian Bureau of Statistics (personal communication).

Raw or processed (i.e. canned, smoked), edible weight only.

Comprises $84 \%$ whole milk, $8 \%$ fat-reduced milk, and $8 \%$ skimmed milk.

Expressed as liquid whole milk equivalents.

** Includes bakery shortening. 
basis of the 'as purchased' equivalent weights of cooked meats. If the beef component of sausages and other small goods were included in the NDSA data for meats this underestimate would be much greater. The $\mathrm{AC}$ data provide: a good indication of lamb and mutton consumption by adults, underestimating this by only $10 \%$ (and $20 \%$ as purchased); a good indication of total ( $1 \%)$, fresh pigmeat consumption $(1 \%)$ and of cured pigmeats $(3 \%)$; and a very poor indication of offal and veal consumption, overestimating adult offal consumption by about $61 \%$ and veal consumption by $80 \%$. If the pigmeat and mutton components of sausages and other smallgoods reported consumed in the NDSA were included as meats, the differences between the AC and NDSA would be very small for these meats as compared with beef.

The overall difference between the total $\mathrm{AC}$ cooked edible portion equivalent weight of meats and NDSA reported intakes (Table 3) is large at $33 \%$, and on a cooked 'as purchased' edible weight comparison (i.e. no fat trimming before consumption) the underestimate increases to $40 \%$. If allowance were made in the AC data for home and retail waste and non-food home use (e.g pet food), this underestimate of adult meat consumption would be even greater. Total AC meats are underestimated by a minimum of $32 \%$ and up to $39 \%$ if allowance for smallgoods is made.

Poultry. The NDSA data for chicken were adjusted down by $0.2 \mathrm{~g}$ for the weight of coatings associated with some chicken dishes reported consumed. Table 3 indicates that the $\mathrm{AC}$ data are a poor representation of chicken consumption of adults, underestimating this by $23 \%$ on an 'as consumed' basis and by $36 \%$ on an 'as purchased' basis. When duck and turkey are included to give a total poultry comparison there is fair agreement between the AC and NDSA data (13\%) and poor agreement on an 'as purchased' basis (25\%), with the AC generally underestimating reported adult poultry consumption, particularly chicken consumption.

Fish, seafood and products. The NDSA data were adjusted down by $1.1 \mathrm{~g}, 0.2 \mathrm{~g}$ and $0.2 \mathrm{~g}$ for fish, crustacea and molluscs, and processed fish respectively, for the non-fish components of mixed dishes. The AC and NDSA data comparisons (Table 3) show that the $\mathrm{AC}$ is a good indicator for fish and a poor indicator for each of the processed fish and crustacea and molluses subgroupings. Relative to the NDSA the AC data underestimates fish (non-processed), and crustacea and molluscs by 5 and $30 \%$ respectively, and overestimates processed fish by $24 \%$. Overall there is good agreement between the two sources of data ( $2 \%$ difference). However, relative to the NDSA reported consumption the $\mathrm{AC}$ underestimates non-processed fish, and crustacea and molluscs consumption by adults by 23 and $30 \%$ respectively.

Milk and milk products. The $\mathrm{AC}$ data are a fair representation of adult liquid milk consumption (Table 3), overestimating reported consumption by $13 \%$. Evaporated and powdered milk consumption by adults also appears to be overestimated by the AC data relative to the NDSA data $(10.7$ and $8.1 \mathrm{~g} v .1 .9$ and $0.9 \mathrm{~g}$ respectively). However, these products may have been reported as made up within the liquid-milk component. Further, a proportion of the AC milk in liquid or powdered form would be included in the NDSA figures of $6.7 \mathrm{~g}$ for yoghurt and $12.7 \mathrm{~g}$ for ice-cream. Cheese consumption by adults is overestimated in the AC data by some $16 \%$, suggesting a fair comparison. Adults reported consuming about twice the amount of cream available per capita. On a liquid-whole-milkequivalent basis the $\mathrm{AC}$ overestimates milk and milk-product consumption reported by adults by $26 \%$.

Eggs. The reported intake of egg is the same as the egg available for consumption (Table 3). However, only eggs reported to be consumed as such are included in the NDSA data as it was not possible to determine the quantity of egg in mixed foods, particularly commercial foods such as cakes and biscuits. The AC data do not include an allowance for 
home production. Both the AC and the NDSA, as shown in Table 3, are therefore likely to underestimate 'as available' and 'as consumed' egg.

Fats and oils. The AC data are in poor agreement with the NDSA for total table fats consumption at $16 \%$ difference (Table 3 ). Butter and margarine are both understated in the NDSA due to the substantial intake of table fats that could not be specified by participants (about a third). However, much of this unspecified fat is, from the type of food that the fat is associated with, estimated to be from bakery commercial shortenings which are most like unfortified cooking margarines in composition (National Health and Medical Research Council, 1990). The category 'other margarine' in the AC data encompasses fortified and unfortified non-table margarines.

A little over one-half of the available cooking (frying) fats and oils are reported in the NDSA. The cooking fats indicated here include lard, dripping, solid cooking fats (e.g. 'Copha', 'Frytol'). These are foods that are likely to have significant wastage both in home and catering use. A small amount of total fat $(2 \cdot 3 \mathrm{~g})$ was included with chocolates, soups and dressings (e.g. mayonnaise). The added fat component of this could not be estimated adequately due to the other potential fat-containing ingredients (e.g. milk, meat, eggs). However, overall the AC data are in poor agreement with the NDSA data for the adult consumption of fats and oils, particularly table fats.

\section{Principal sources of fat in adult diets}

As shown in Table 4, spreads and cooking fats, meats and poultry, and milk and milk products together provide 93 and $87 \%$ of the total fat in the AC and NDSA respectively. The higher fat from non-animal foods in the NDSA is due to an underestimate of added fats in some mixed foods (estimated to be in the order of $2 \mathrm{~g}$ ), and the consumption of fatcontaining foods such as cereals and nuts at levels above the per capita mean. Both the AC and the NDSA data rank spreads and cooking fats as the major source of fat in the adult diet, providing 51.9 and $41.8 \%$ of the total respectively. While the AC data clearly show that table spreads and cooking fats are equivalent sources of available dietary fat, the NDSA suggest that the table spreads are the more significant source in the diet of adults. It should be noted that the AC table spreads include the bakery shortenings (i.e. the fats used in commercial cakes, biscuits and pastries). The NDSA then ranks meat and poultry $(24 \cdot 7 \%)$ ahead of milk products $(17 \cdot 3 \%)$. The AC suggests that these two foods areas are virtually equivalent sources of fat in the diet (milk and products $19.0 \%$, cooked meat and poultry $19.4 \%$ ). In terms of the total dietary intake, fat as a percentage of energy is considerably higher in the NDSA $(37.5 \%)$ than in the AC $(32.4 \%)$.

Spreads and cooking fats, meat and poultry, and milk and milk products together provide 39.1 and $44.0 \%$ of the total energy in the AC and NDSA respectively. On this basis the AC and NDSA suggest similar total intakes of these major fat-contributing foods. However, the relative importance of the food sources varies: for example, the contribution to energy by meat and poultry is $49 \%$ greater in the NSDA than in the AC. The fats and oils rank ahead of milk and milk products or meat and poultry $(16.8 \%, 11.3 \%$ and $11 \%)$ in the $\mathrm{AC}$ as a source of energy. In the NDSA, meat and poultry rank ahead of fats and oils or milk and milk products $(16.4 \%, 15.7 \%$ and $11.9 \%)$.

These data show that the AC underestimate the total contribution of fat to the adult diet, giving a greater emphasis on cooking fats and a lower emphasis on meat than is suggested by the NDSA. Both the AC and the NDSA indicate that added fats and oils, including fat spreads, contribute a similar proportion of the total dietary energy $(16.8 \%$ and $15.7 \%)$. However, the $\mathrm{AC}$ data suggest that fat spreads and cooking fats and oils contribute about equally to this $(8.8 \%$ and $8 \%$ ) while in the NDSA the fat spreads are clearly the major contributor, $9.8 \%$ of total energy compared with $5.7 \%$ from cooking fats and oils. The 
Table 4. Per capita fat and energy consumption/d: apparent consumption $(A C)$ data* and National Dietary Survey of Adults (NDSA) data

\begin{tabular}{|c|c|c|c|c|c|c|c|c|}
\hline \multirow[b]{2}{*}{ Food } & \multicolumn{2}{|c|}{ Fat $(\mathrm{g})$} & \multicolumn{2}{|c|}{ Energy $(\mathrm{kJ})$} & \multicolumn{2}{|c|}{ Fat $(\%$ total $)$} & \multicolumn{2}{|c|}{ Energy $(\%$ total $)$} \\
\hline & $\mathrm{AC}$ & NDSA & $\mathrm{AC}$ & NDSA & $\mathrm{AC}$ & NDSA & $\mathrm{AC}$ & NDSA \\
\hline Total meat & $17 \cdot 7$ & $19 \cdot 8$ & 1145 & 1266 & $16 \cdot 0$ & $21 \cdot 3$ & $9 \cdot 1$ & $13 \cdot 8$ \\
\hline Beef and veal & $6 \cdot 2$ & $8 \cdot 7$ & 462 & 600 & $5 \cdot 6$ & $9 \cdot 4$ & 3.7 & $6 \cdot 6$ \\
\hline Lamb, mutton & $5 \cdot 1$ & $4 \cdot 4$ & 301 & 296 & $4 \cdot 6$ & 4.7 & 2.4 & $3 \cdot 2$ \\
\hline Pigmeat & $5 \cdot 3$ & $3 \cdot 3$ & 300 & 188 & 4.8 & 3.6 & $2 \cdot 4$ & $2 \cdot 1$ \\
\hline Offal & $1 \cdot 1$ & 0.4 & 82 & 31 & 1.0 & 0.4 & 0.6 & $0 \cdot 3$ \\
\hline Other & NA & $3 \cdot 0$ & NA & 151 & NA & $3 \cdot 2$ & NA & $1 \cdot 6$ \\
\hline Poultry & $3 \cdot 7$ & $3 \cdot 2$ & 237 & 238 & $3 \cdot 4$ & $3 \cdot 4$ & 1.9 & $2 \cdot 6$ \\
\hline Fish, seafood and products & 0.8 & 0.6 & 101 & 84 & 0.7 & 0.7 & 0.8 & 0.9 \\
\hline Total milk and milk products & $21 \cdot 0$ & $16 \cdot 1$ & 1426 & 1087 & $19 \cdot 0$ & $17 \cdot 3$ & $11 \cdot 3$ & $11 \cdot 9$ \\
\hline Egg & $2 \cdot 1$ & $2 \cdot 1$ & 124 & 116 & 1.9 & $2 \cdot 3$ & $1 \cdot 0$ & $1 \cdot 3$ \\
\hline Total fats and oils & 57.3 & $38 \cdot 8$ & 2120 & 1436 & 51.9 & $41 \cdot 8$ & $16 \cdot 8$ & $15 \cdot 7$ \\
\hline All spreads & $30 \cdot 0$ & $24 \cdot 2$ & 1110 & 896 & $27 \cdot 2$ & $26 \cdot 0$ & 8.8 & $9 \cdot 8$ \\
\hline Cooking fats, oils & $27 \cdot 3$ & $14-6$ & 1010 & 540 & $24 \cdot 7$ & $15 \cdot 1$ & 8.0 & $5 \cdot 9$ \\
\hline All other foods & $7 \cdot 8$ & $12 \cdot 3$ & 7460 & 4928 & $7 \cdot 1$ & $13 \cdot 2$ & $59 \cdot 1$ & $53 \cdot 8$ \\
\hline Total intake & $110 \cdot 4$ & $92 \cdot 9$ & 12613 & 9155 & & & & \\
\hline Fat as $\%$ total energy & & & & & & & $32 \cdot 4$ & 37.5 \\
\hline
\end{tabular}

NA, not applicable.

* Nutrients for cooked edible meats, fish, poultry and egg.

latter is consistent with the expectation of higher wastage of cooking fats and oils than spreads. It may also reflect a lower consumption of certain foods that contain added fats and oils (e.g. take-aways, savoury snacks such as potato crisps, extruded cheese snacks) by adults aged 25 to 65 years than by other age groups in the population.

In terms of their contribution to total fat and energy, meats and poultry rank about equally with milk and milk products behind total fats and oils in the AC. In the NDSA, meats and poultry rank after fats and oils as a source of fat, and ahead of this group as a contributor to total energy. Total milk and milk products are well behind both fats and oils and meats and poultry as contributors to both total fat and energy in the NDSA. Within the meats and poultry group the AC suggests a lower contribution by beef and veal to the total contribution of meats and poultry to both fat and energy (29\% and $33.4 \%)$ than in the NDSA (37.8\% and $39.9 \%)$. This contribution to fat and energy in the NDSA becomes greater when the smallgoods contribution $(13 \%$ and $10 \%)$ is also considered. In the NDSA, pigmeat and poultry rank well behind beef and veal as contributors to the fat and energy provided by the meats and poultry group compared with the AC.

Clearly these two data sets provide different information about the principal sources of dietary fat in Australia. The population has available a food supply in which added fats and oils contribute $51.9 \%$ of the total fat, and meats and poultry, and milk and milk products about $19 \%$ each. The NDSA suggests that the sub-population group of adults aged 25-64 years chooses a diet from this food supply that is higher in total fat (as a percentage of total energy) and in which meats and poultry play a greater role, and milk and milk products a lower role, in contributing to their fat intake. These results have implications for the development of appropriate food and nutrition targets for levels and types of fat in the food 
system and for the development of programmes to meet these targets in the diets of particular population groups.

\section{DISCUSSION}

\section{Fat sources in the diet: $A C$ and NDSA}

The accuracy of the $\mathrm{AC}$ data for quantities of meat available for consumption has recently been supported by a household purchasing survey of meat, poultry and fish conducted in 1984 by the Australian Bureau of Agricultural and Resource Economics (ABARE; Bartley et al., 1988). This survey collected data in 2-week meal and expenditure diaries in 424 and 468 households in Sydney and Melbourne respectively. The results showed that the per capita weekly household purchases were $1.3 \mathrm{~kg}$ retail meat, including smallgoods (adjusted for cured pigmeats) and excluding meat used for pet food, which covered $87 \%$ of all meals. This compares well with the $1.6 \mathrm{~kg}$ carcass weight equivalent available per capita reported by the AC. The $18 \%$ difference between AC carcass and ABARE retail weight is of the same order as that given in Table 2 where the retail cut proportion of the carcass as provided by the Meat and Allied Trades Federation varies from 71.5 to $82.75 \%$. Allowance must be made for the possible meat component of the $13 \%$ of meals consumed away from home in the ABARE study. For beef and lamb and/or mutton the ABARE data were within $10 \%$ of the $\mathrm{AC}$, while those for pigmeat (equivalent) and offal were about one-half that of the AC data. The validity of the AC data for poultry is supported by the Australian Poultry Industries Association's production data that $90 \%$ of the poultry available is chicken (Fairbrother, 1987), with the remainder being duck and turkey. When allowance is made for forms of chicken purchased the ABARE data for poultry is also generally supportive of the AC data.

Independent studies have proposed raw and cooked edible weight factors for carcass meats that support the validity of factors used in this paper to estimate edible weight of food consumed (Fantini \& MacDonald, 1987; Warren \& Channon, 1990). The Australian Meat and Livestock Corporation (AMLC) has suggested that the appropriate factors for determining raw retail weight of lamb and beef carcass meats are 75 and $65 \%$ respectively (Fantini \& MacDonald, 1987) compared with the 82 and $72 \%$ advised by the Meat and Allied Trades Federation (personal communication) and used in this paper. These factors include inedible components such as bone and gristle and when allowance is made for this the respective factors derived for raw edible weight of meat, as shown in Table 2, are 63 and $66 \%$. Carcass yield (boneless trimmed retail raw weight of meat) studies from a programme run by the Victorian Department of Agriculture and Rural Affairs and the AMLC report equivalent factors for lamb (59-66\%; Warren \& Channon, 1990). The factors which the AMLC pilot study determined for 'estimated cooked meat eaten' (i.e. cooked weight of carcass meat minus retail wastage, trimming and loss and consumer fat, bone and plate waste) were 38 and $42 \%$ for lamb and beef respectively, compared with 42 and $41 \%$ as derived in Table 2. Overall the revised carcass factors used in this study for raw edible weight and for deriving cooked edible weight of $\mathrm{AC}$ meats are supported by these literature reports.

The underestimation by the $\mathrm{AC}$ of adult consumption would be due in part to the lower consumption of meat and poultry by younger people. The reported meat consumption data from the national dietary survey of schoolchildren aged 10-15 years (NDSSC; English et al. 1988) suggests that this age group, which comprises just over $10 \%$ of the total population, consumes about $25 \%$ less meat and about $50 \%$ less chicken than adults. It would be expected that younger children consume even less $(0-9$ years, $16.1 \%$ of population). There are no data available for this age group nor for those aged 16-24 years and 65 years plus in Australia. While the NDSA data are considerably lower than the $\mathrm{AC}$ for duck and turkey intake, this would reflect the time of year (May to November) that 
the survey was undertaken. These products, particularly turkey, show seasonal variation in consumption. More are consumed in the Christmas holiday season than at other times of the year. The NDSA did not include this period.

It is possible that the NDSA could have overestimated the consumption of meats and chicken. However, the $24 \mathrm{~h}$ recall method is generally reported to underestimate rather than overestimate intake, particularly for foods that are eaten in large quantities (Block, 1982; Bingham, 1987).

The adequacy of the AC data for non-commercial sources of non-processed fish, crustacea and molluses has been questioned (Commonwealth Department of Primary Industry (CDPI), 1978). The AC includes an allowance of $10 \%$ of commercial production for fish caught during leisure (termed 'home-production'), but none for crustacea and molluscs. A survey, commissioned by the CDPI in 1976-77, of 6000 households in all State and Territory capital cities except Darwin reported that $27 \%$ of fresh fish and about $16 \%$ of seafood (crustacea and molluscs) was 'caught or received as a gift'. The report suggested that the available fish and seafood is some $30 \%$ greater than that represented by commercial production. Such an increase in the 'home production' component of the AC (20 and $30 \%$ respective to non-processed fish and crustacea and molluscs) and assuming it was all eaten within Australia (i.e. none exported), would increase $\mathrm{AC}$ fish by $1 \mathrm{~g}$ and crustacea and molluscs by $1.6 \mathrm{~g}$ resulting in good comparisons between the $\mathrm{AC}$ and the NDSA data for both.

Overall, if the changes to AC proposed by the CDPI report were made the AC would overestimate adult consumption of fish, seafood and products by $13 \%$ relative to the NDSA. However, the NDSA itself may underestimate the per capita fish consumption by adults. The 1976-77 survey (Commonwealth Department of Primary Industry, 1978) showed that the percentage of meals at which fish was eaten was highest on Friday at $21.3 \%$, relative to $13-14.4 \%$ on other days; and for crustacea and molluscs it was highest on Friday, $18.3 \%$, Saturday, $22 \cdot 2 \%$, and Sunday, $19 \cdot 6 \%$ relative to $8 \cdot 3-12 \cdot 3 \%$ on other days. As described earlier, the NDSA did not cover Saturdays, and Fridays were grossly under-represented. While eating fish on Fridays may have reduced somewhat since 1976-77 with the relaxation of this religious dietary requirement, the data suggest that the NDSA will have underestimated fish consumption. As a corollary, meat is likely to have been overestimated in the NDSA.

The ABARE survey data on fish and 'other seafood' purchases (including self caught/gifts) tend to support the CDPI contention that the AC data underestimate the fish available for consumption.

Differences observed between the AC and the NDSA milk data are, in part, due to the method of recording milk. Despite the fact that milk is a component of many mixed foods (e.g. biscuits, cakes, desserts, etc.), due to the method of recording the milk component for home-made mixed foods as a separate item, most of the milk in mixed foods is identifiable in the NDSA. Commercial mixed foods recorded in the NDSA as a single food item have only a small contribution to make to the milk and milk products reported in Table 3.

The AC and NDSA are in poor agreement with regard to total-milk-equivalent milk intake with the AC generally overestimating milk-product intake by $20 \%$ relative to the NDSA data, undoubtedly due to marked differences in consumption between adults and children. The national dietary survey of schoolchildren aged 10-15 years (English et al. 1988 ) reported a $25 \%$ higher per capita consumption of total milk products than that of adults. Further, there is a much greater quantity of milk and milk products 'hidden' in mixed foods in the NDSSC due to differences in the method of data collection. This age group represents $10 \%$ of the Australian population. If this higher intake is also true in children less than 10 years (16\% of the population) and adolescents of $16-18$ years $(5 \%$ 
of the population), it would suggest that the $\mathrm{AC}$ is a good indicator of milk consumption per capita of population, but overestimates adult consumption. The higher cream consumption reported in the NDSA may be a reflection of adult consumption of sauces, desserts or restaurant foods. The differences in food choices of different age groups are also reflected in other milk products. Adults reported consuming about twice as much cheese as children aged 10-15 years, but only one-third the quantity of ice-cream and ice confections.

The AC and NDSA report equivalent egg data. However, these data are probably an underestimate of available egg and adult consumption of egg. The NDSA data do not include the quantity of egg consumed as part of mixed foods and the $\mathrm{AC}$ does not include an allowance for home production of egg. Another study (based on data from dietary surveys using the food frequency method) estimated total mean daily egg consumption of adults as about $17.5 \mathrm{~g}$ and about $13 \mathrm{~g}$ for 10-year-old children (Baghurst, 1988). Given the lower reported intake of schoolchildren also reported by English et al. (1988), the good agreement between the AC and the NDSA is suspect and suggests that egg consumption has been under-reported and/or the egg component of mixed foods underestimated in the NDSA.

Although the agreement between the AC and the NDSA data for consumption of fat spreads is only rated as fair, the AC overestimating adult consumption by $16 \%$, the agreement is much better than expected. This agreement is no doubt assisted by the approach taken by the NDSA to specify usage of fats as spreads and in cooking. Relative to the NDSA data the AC overestimates the reported adult consumption of cooking (frying) fats and oils by some $47 \%$. For some foods it was difficult to estimate the potential added fats (e.g. certain salad dressings, soups) resulting in a small underestimate of total fats estimated consumed in the NDSA. Considering this and the expected but unquantifiable waste of cooking fats and oils, both in home and commercial use, the $\mathrm{AC}$ and the NDSA differences are decreased. Further, the higher consumption by schoolchildren of high added-fat foods such as pastries and fried take-away foods (English et al. 1988) suggests that this age group has higher consumption levels of these added fats than adults.

Overall, as a proportion of total energy the $\mathrm{AC}$ data provide an underestimate of the amount of animal foods in the adult diet. This is reflected in both the higher fat contribution reported in the NDSA $(37.5 \%)$ and the lower energy contribution from nonanimal foods $(53.8 \%)$ compared with the $\mathrm{AC}(32.4 \%$ and $59 \cdot 1 \%$, respectively). Further, the relative importance of specific animal foods as sources of both fat and energy in the diet varies between the two data sets.

\section{$A C$ as an estimate of fat consumption}

Adjusting the AC 'raw foods' to 'cooked as purchased' form (untrimmed for meats) reduced the total fat from $118.8 \mathrm{~g}$ (Australian Bureau of Statistics, 1990) to $110.4 \mathrm{~g}$ and total energy from $12959 \mathrm{~kJ}$ to $12613 \mathrm{~kJ}$ per capita/d. This decrease in fat is due primarily to fat lost in the cooking of meats and poultry (from $29.6 \mathrm{~g}$ fat in the raw food to $21.4 \mathrm{~g}$ fat in the cooked food). This has the effect of decreasing the proportion of energy from fat from $33.9 \%$ to $32.4 \%$. These changes are small, but there is a larger change in the ranking of foods as sources of fat. When the 'cooked as purchased' basis is used, meat drops from second position at $21 \%$ of total fat (raw basis; Australian Bureau of Statistics, 1990) to third position at $16 \%$ of total fat (behind fats and oils, and milk and milk products).

\section{Relevance to national food policy and planning}

Dietary fat and its sources are prominent in the recommendations made in many countries for the promotion of health and the prevention of diet-related disease. In the recently 
revised Dietary Guidelines for Australians (National Health and Medical Research Council, 1992) the recommendations were for the first time placed in order of priority. Of the eight major and two subsidiary recommendations, that relating to fat, "eat a diet low in fat and, in particular, low in saturated fat', was ranked third after the recommendations for dietary variety and increased consumption of cereals, vegetables and fruit. These dietary guidelines form the basis on which strategies to implement the Australian Food and Nutrition Policy across the food system are to be developed and monitored (Commonwealth Department of Health, Housing \& Community Services, 1992).

A key issue for any national food and nutrition policy is the availability of a nutritionally adequate food supply which meets the RDI and is supportive of policy objectives in such areas as dietary guidelines and food quality.

With respect to recommendations to reduce fat in the national diet, the present study clearly emphasizes the primary role of added fats and oils (51.9\% of available fat) in determining the total available fat, and influencing the types of fat available for consumption. Much of this fat is used in the manufacture of processed foods, and in commercial catering. The study shows that, for adults, the total consumption of fats and oils is $38.8 \mathrm{~g}$ (Table 4). Adults reported spread consumption as $16 \mathrm{~g}$ in the NDSA, therefore about $60 \%$ of fats and oils are 'hidden' in mixed and cooked foods.

While there is scope for some reduction of fat through the trimming of the separable fat of meat and poultry, most of the potential reduction of fat in this food group has already been achieved through the shift in the 1980 s to leaner retail meats. Beef, veal, lamb and pork are now, respectively, 15-50, 50, 20-60 and 20-40\% leaner than the leveis reported in the 1970s (Greenfield, 1987). This does not hold for chicken which has increased its fat content (Greenfield, 1987). At the food supply level, a further focus on the production and commercial reward for leaner animals, including poultry, to ensure a reduction in total meat fats entering the food system (in the form of cooking fats and food ingredients) and a consideration of the potential for fat-reduced processed meats, may be the most effective strategies.

The increased availability of reduced-fat forms of milk products on the market may also reduce the available fat in the Australian diet. These foods contribute $19 \%$ of the fat. This again implies the importance of focusing on the production and reward issues to ensure that there is a true reduction in milk fats in the food supply.

The present study shows that with fat at $32.4 \%$ of energy the per capita food supply is already closer to the recommended dietary target for fat $(33 \%)$ than that suggested by the consumption levels of adults. The percentage of energy from fat is lower and that from cereals, fruit and vegetables is higher in the food supply than reported by adults in the NDSA. This suggests that food choices by particular population groups need to be investigated and incorporated into strategies for change directed at different levels in the food system, and for different population groups.

Thus, reports comparing AC data and NDSA data per se that have concluded that AC overstates total food intake, the proportion of fat in the diet and, in particular, meat as a source of fat (Australian Meat and Livestock Corporation 1988, Australian Nutrition Foundation, 1989) were wrong with respect to adults aged 25-64 years. Incorrect conclusions such as those mentioned could result in ill-conceived approaches to reducing fat in the diet of adults.

Similarly availability and consumption of sugars and alcohol require further analysis due to the operation of other factors which render them difficult to compare between the AC and the NDSA in the formats originally published. The AC are the best objective indicators of the levels and trends in the consumption of these foods by Australians. Further, for all foods, the AC provide levels and trends in the foods available that, while dependent on the 
quality of the censuses conducted, are substantially unaffected by the many and complex issues that can influence food choices and reported intakes obtained by dietary survey methods. Such issues include seasonal availability of foods, food distribution, food access (e.g. food distribution, food outlet location, food cost), age, sex and cultural influences, food knowledge and language, literacy and numeracy skills.

The NDSA and similar consumption surveys are, however, critical to the development and monitoring of strategies and programmes to achieve change in particular population groups. With AC data being available on a more frequent basis (annually) than nationally representative dietary surveys in Australia, they provide a baseline and a much needed facility for monitoring change. Evaluation of the dietary profile of a population group against the $\mathrm{AC}$ data provides a basis for the use of $\mathrm{AC}$ to monitor and predict the effect of food supply changes at the level of a population group.

This study highlights the role and need for information on foods, food and nutrient intake at different levels in the food supply for effective development, implementation and monitoring of national food and nutrition policy and planning.

\section{Areas for improving the $A C$ data}

The very similar factors for cooked carcass yield obtained by the AMLC allow for a fattrimming component which those in Table 2 do not, consistent with current ABS practice. The AC data are always provided for foods as produced. This policy is supported as it provides a data series on foods available that is consistent over time. Thus, for consistency between past and future data these factors should be based on average retail percent weight of meat per carcass produced by butchers. Adjustments for consumer practices such as meat-trimming and edible plate waste should be estimated on the basis of data relevant to the population under study at the time.

Studies on carcass yield factors for both the range of carcass classifications available for beef, lamb, veal, pork and poultry, and on the retail yields by 'cut' from such carcasses, would improve the relevance of the AC data. Such studies would need to be carried out on a regular basis (e.g. every 5-10 years). It would be desirable to include a co-operative component on gross composition studies of retail cuts including, as necessary, weight changes on cooking and on the impact, if any, of consumer meat-trimming practices on the quantity of meat consumed. Data on turkey and duck are particularly needed within the poultry category. Information on the use of meats and poultry in manufactured meats, and the type and quantity of these products in the food supply is also needed. Non-food use of meats for pets could also be included. The retail and consumer aspects of the suggested studies would enable the $\mathrm{AC}$ data to provide better indicators of trends in meat and poultry consumption both as foods and as contributors of nutrients.

The AC data would be improved if the 'home production' allowances for a number of foods were reviewed and updated by the AC compilers, particularly foods such as fish, eggs, poultry, fruit and vegetables which can be 'produced' readily by most households. The growth in leisure in recent years and the public's concern about the use of chemicals in commercial food production suggest that a review of home grown fruit and vegetable products would be particularly timely. From this study it also appears desirable for consumption surveys to seek specifically the detail of information on commercial mixed foods likely to contain eggs (e.g. brand names) that would allow estimations of consumption by population subgroups to be made.

The AC data for cooking fats and oils are quite crude with respect to the specific fats included, and an update of both the quantity and specific types of non-spread edible fats and oils is needed. Similarly, the classifications for fat spreads need to be reviewed since 
they now encompass fat-reduced products, mixed milk- and vegetable-fat products and polyunsaturated products. These should all be identified.

There is also the potential for more information on the use of major foods in the production of value-added products, particularly those where the major effect is to add fat, or sugar or salt. For example, the AC currently provide information on the major tomatobased products (e.g. canned tomato, tomato paste, tomato soup, tomato puree) as well as fresh tomatoes available. Such data on the major processed forms of other fruits and vegetables such as the potato (i.e. potato crisps, pre-prepared potato chips, dehydrated and canned potato), or sweet corn (canned, corn chips, polenta etc.) or unsweetened forms of processed fruits would be useful in monitoring progress towards achieving the dietary guidelines.

\section{Areas for improving national dietary surveys}

Future national dietary surveys should obtain more detailed information on the specific foods eaten, particularly cooking methods, degree of fat trimming of meat, brand names and where foods were purchased and/or consumed. This would allow more differentiation between commercial products (e.g. in amount of egg added, exact types of fat used), and the nature of foods consumed at home or outside the home. Fish and seafood consumption data (and as a corollary, meat consumption data) could be improved in future national surveys by ensuring a better representation of all days of the week. 'Cream' should be differentiated from 'artificial cream' in future dietary surveys, and all sugar and fat substitutes should be identified adequately, both used directly and as components of mixed foods. Such information together with an increased volume of up-to-date and specific food composition data would improve the reliability of the final results obtained.

\section{CONCLUSIONS}

The importance of appropriate choice and use of method of recording food intake data was recently demonstrated by Crane et al. (1992) whose US study showed that food-supply and food-survey statistics may show different trends over time. For example, in their study food-supply data indicated an increase in dietary fat, whereas survey data showed a decrease. In many countries, including Australia, national food disappearance statistics are an important national and international nutrition resource used by researchers, particularly epidemiologists, and nutrition policy markers. Compared with dietary surveys, AC figures provide cost effective, consistent and timely information and should have a primary place in national food and nutrition monitoring programmes. Their usefulness is greatly enhanced if the user is conversant with the origins of such data, their interpretation and their potential relative to dietary consumption data.

The data reported in the present study highlight the importance of using an appropriate basis for comparing data from sources that use different methods of data collection, particularly where the data represent different forms of the same food. Specifically, for comparing reported mean intake and per capita food supply data of meat, consideration must be given to variables such as equivalent weights, equivalent forms of the food and the inclusion of all sources of the food (e.g. processed meats).

In countries where food disappearance statistics are the main source of data on trends in the national diet, supplemented by very limited national dietary survey data, as is the case in Australia, appropriate comparisons of these data sets can enhance their usefulness. The present study shows that such a comparison can provide a basis for determining where a particular population subgroup's reported food consumption deviates from the national per capita available food. Such information can then be used to assess more appropriately AC trends pertinent to those of population subgroups, e.g. adult food consumption trends. 
Generally, the present comparison of $\mathrm{AC}$ and NDSA data did not support the view that the $\mathrm{AC}$ data are a poor indicator of foods consumed by adults, and that the AC data represent a gross overestimation of the quantity of food consumed by adults. The study shows that relative to adult meat consumption the $\mathrm{AC}$ data underestimate reported total 'fresh' meat consumption by about $27 \%$, including allowances for factors such as wastage, non-food use and fat trimming. When smallgoods and offal are included the AC underestimates total adult meat consumption by $32 \%$ and, if compared on an 'as purchased' basis (without allowance for fat-trimming of meat at the point of consumption), by nearly $40 \%$.

The findings of the present study conflict with others which claim that AC data overestimate the quantity of meat eaten (Fantini \& MacDonald, 1987; Australian Meat and Livestock Corporation, 1988; Australian Nutrition Foundation, 1989). Comparisons that ignore the inedible components of carcass meats and potential weight losses on cooking which act to 'decrease' the AC value for available per capita meat, and/or ignore the meat component of meat products or mixed dishes which 'increase' the dietary survey values for meat consumption can only lead to erroneous conclusions.

The present study also shows that the AC data: are a good indicator of fish and seafood, and pigmeat consumption; are a fair indicator of milk, cheese, and table spreads consumption; and overestimate total cooking fats and oils consumption reported by adults.

While much of the discussion and many recommendations of nutrition policy and programmes focus on levels of nutrient intake, ultimately it is the foods eaten that are important. Trends in food consumption provide an important basis for identifying dietary problems, for proposing solutions and evaluating the efficacy of resultant programmes. The data comparisons made here provide a means for using food disappearance data more appropriately to gauge trends in adult food consumption.

The present study indicates that there is a need for similar studies which examine other nutrients of importance in the Australian Diet, such as dietary fibre, sugars, and alcohol.

Thanks to the Australian Department of Community Services and Health (DCSH) and the National Heart Foundation of Australia for access to detailed data from the NDSA, and to Anne-Marie Waters, DCSH for computer programming assistance.

\section{REFERENCES}

Advisory Council on Nutrition (1937a). Third Report of the Advisory Council on Nutrition to the Minister for Health. Canberra: Commonwealth Government Printer.

Advisory Council on Nutrition (1937b). Fourth Report of the Advisory Council on Nutrition to the Minister for Health. Canberra: Commonwealth Government Printer.

Advisory Council on Nutrition (1939). Final Report of the Advisory Council on Nutrition to the Minister for Health. Canberra: Commonwealth Government Printer.

Australian Bureau of Statistics (1985). Apparent Consumption of Foodstuffs and Nutrients, Australia 1983-1984. Canberra: ABS

Australian Bureau of Statistics (1987). Estimated Resident Population by Sex and Age: States and Territories of Australia June 1981 to June 1987. Canberra: ABS.

Australian Bureau of Statistics (1988). Apparent Consumption of Foodstuffs and Nutrients, Australia $1986-1987$. Canberra: ABS.

Australian Bureau of Statistics (1990). Apparent Consumption of Foodstuffs and Nutrients, Australia 1987-1988. Canberra: ABS.

Australian Meat and Livestock Corporation (1988). Meat. The Facts. At Last. Sydney: AMLC.

Australian Nutrition Foundation (1989). A Review of Beef, Veal and Lamb in the Australian Diet. Sydney: ANF.

Baghurst, K. (1988). Intakes and Sources of Egg and Poultry Items in Various Australian Populations and their Relationship to Biomedical Status. A Report to the Poultry Research Council. A Report to the Chicken Meat Research Council. Adelaide: CSIRO Division of Human Nutrition.

Baghurst, K. I., Crawford, D. A., Worsley, A. \& Record, S. J. (1988). The Victorian nutrition survey - intakes 
and sources of dietary fats and cholesterol in the Victorian population. Medical Journal of Australia 149, $12-20$.

Bartlev, S., Ball, K. \& Weeks, P. (1988). Household Meat Consumption in Sydney and Melbourne. Discussion Paper 88.2. Canberra: Australian Government Publishing Service.

Bingham, S. (1987). The dietary assessment of individuals; methods, accuracy, new techniques and recommendations. Nutrition Abstracts and Reviews (Series A) 57, 705-742.

Block, G. (1982). A review of validations of dietary assessment methods. American Journal of Epidemiology 115, 492-505.

Cashel, K., English, R., Bennett, S., Berzins, J., Brown, G. \& Magnus, P. (1986). National Dietary Survey of Adults. Report No. 1. Foods Consumed. Canberra: Australian Government Publishing Service.

Cashel, K., English, R. \& Lewis, J. (1989). Composition of Foods Australia. Canberra: Australian Government Publishing Service.

Castles, 1. (1986). Australian Demographic Trends. Canberra: Australian Bureau of Statistics.

Commonwealth Bureau of Census and Statistics (1948). Report on Food Production and the Consumption of Foodstuffs and Nutrients in Australia. Canberra: CBCS.

Commonwealth Department of Health, Housing and Community Services (1992). Food and Nutrition Policy. Canberra: Australian Government Publishing Service.

Commonwealth Department of Primary Industry (1978). Fish and Seafood Consumption in Australia. A Consumer Survey. 1976-1977. Canberra: Australian Government Publishing Service.

Crane, N. T., Lewis, C. J. \& Yetley, E. A. (1992). Do time trends in food supply levels of macronutrients reflect survey estimates of macronutrient intake? American Journal of Public Health 82, 862-865.

Dwyer, T. \& Hetzel, B. S. (1980). A comparison of trends in coronary heart disease mortality in Australia, USA, England and Wales with reference to three major risk factors-hypertension, cigarette smoking and diet. International Journal of Epidemiology 9, 65-71.

English, R. (1987). Towards Better Nutrition for Australians. Report of the Nutrition Taskforce of the Better Health Commission. Canberra: Australian Government Publishing Service.

English, R., Cashel, K., Lewis, J., Bennett, S., Berzins, J., Waters, A. \& Magnus, P. (1988). National Dietary Survey of Schoolchildren Aged 10-15 Years. Report No. 1. Foods Consumed. Canberra: Australian Government Publishing Service.

English, R., Lewis, J. \& Cashel, K. (1990). Composition of Foods, Australia. Vol. 2. Canberra: Australian Government Publishing Service.

Fantini, L. \& MacDonald, N. (1987). Trends in meat consumption in Australia 1938-1939 to 1983-1984. Food Technology Australia 39, 187-190.

Fairbrother, J. (1987). Trends in poultry meat consumption. Food Technology Australia 39, 191-193.

Food and Agriculture Organization (1980). Food Balance Sheets. Rome: FAO.

Food and Agriculture Organization (1984). Food Balance Sheets. Rome: FAO.

Greenfield, H., (1987). The nutrient composition of Australian meats and poultry. Food Technology Australia 39, $181-240$.

Greenfield, H., Chuah, L. K. \& Wills, R. B. H. (1981). Composition of Australian foods. 12. Hamburgers. Food Technology Australia 33, 619-620.

Greenfield, H. \& Kosulwat, S. (1991). Nutrient composition of Australian fresh retail sausages and the effects of cooking on fat content. Journal of the Science of Food and Agriculture 57, 65-75.

Greenfield, H. Lerogiannis, V., Makinson, J. \& Wills, R. B. H. (1983). Composition of Australian foods. 19. Greek foods. Food Technology Australia 35, 84-86.

Health Targets and Implementation Committee (1988). Health for All Australians. Report to the Australian Health Ministers' Advisory Council and the Australian Health Ministers' Conference. Canberra: Australian Government Publishing Service.

Langsford, W. A. (1979). A food and nutrition policy. Food and Nutrition Notes and Reviews 36, $100-103$.

Lewis, J. \& English, R. (1990). Composition of Foods Australia. Volume 3. Canberra: Australian Government Publishing Service.

National Health and Medical Research Council (1945). The Food Consumption and Dietary Levels in 2730 Australian Family Households in 1944. Canberra: Commonwealth Government Printer.

National Health and Medical Research Council (1989). Implementing the Dietary Guidelines For Australians. Report of the Subcommittee on Nutrition Education. Canberra: Australian Government Publishing Service.

National Health and Medical Research Council (1990). Foods Standards Code. Canberra: Australian Government Publishing Service.

National Health and Medical Research Council (1992). Dietary Guidelines For Australians. Canberra: Australian Government Publishing Service.

National Heart Foundation (1984). Risk Factor Prevalence Study No. 2-1983. Canberra: NHF.

Newell, G. \& Skurray, G. (1987a). Food consumption trends and the Australian dietary guidelines: Are they consistent? Journal of the Home Economics Association of Australia 19, 30-31.

Newell, G. \& Skurray, G. $(1987 \mathrm{~b})$. Changes in the apparent consumption of foods and nutrients in Australia: 1975-1976 to 1983-84. Food Technology Australia 39, 242-245, 253. 
Pao, E., Sykes, K. \& Cypel, Y. (1989). USDA Methodological Research for Large-scale Dietary Intake Surveys, 1975-1988. Washington: USDA.

Paul, A. A. \& Southgate, D. A. T. (1978). McCarnce and Widdowson's The Composition of Foods, London: H. M. Stationery Office.

Saxelby, C. (1987). Pork consumption trends and consumer attitudes. Food Technology Australia 39, $194-195$.

Thomas, S. \& Corden, M. (1977). The Metric Tables of Composition of Australian Foods. Canberra: Australian Government Printer.

Warren, B. \& Channon, H. (1990). Lamb Cutting Notes 1. More Fat Means Less Saleable Meat. Victoria: Rutherglen Research Institute.

Wills, R. B. H. \& Greenfield, H. (1982a). Composition of Australian foods. 17. Snack foods. Food Technology Australia 34, 452-455.

Wills, R. B. H. \& Greenfield, H. (1982b). Composition of Australian foods. 18. Foods from Kentucky Fried Chicken. Food Technology Australia 34, 566-569.

Wills, R. B. H., Makinson, J. \& Greenfield, H. (1981). Composition of Australian foods. 9. Meat pies, sausage rolls and pasties. Food Technology Australia 33, 450-454.

Wills, R. B. H., Myers, P. R. \& Greenfield, H. (1982). Composition of Australian foods. 14. Margarines and cooking fats. Food Technology Australia 34, 240-244.

Working Party on Food and Nutrition Policy (1984). Making Food Choices Easy Choices. Towards a Food and Nutrition Policy for Victoria. Report of a Working Group Prepared for the Standing Committee of Health and Agriculture. Melbourne: Government Printer. 